\title{
REVIEW
}

\section{The pandemic influenza threat: a review from the primary care perspective}

\author{
Lee Gan Goh ${ }^{a, b}$, Pak Yean Cheong ${ }^{a, c, *}$
}

a Department of Community, Occupational \& Family Medicine, Yong Loo Lin School of Medicine, National University of Singapore, Blk MD3, 16, Medical Drive, Singapore 117597

${ }^{\mathrm{b}}$ Asian-Pacific Region, WONCA

c Singapore College of Family Physicians

Received 30 March 2006; accepted 16 April 2006

\section{KEYWORDS}

Pandemic influenza

threat;

WHO;

Preparedness Plan; Infection control measuies:

Voluntary isolation

\section{Summary}

Aims: This paper aims to summarice th $\epsilon$ grwing 1 terature concerning an imminent future influenza faidemin iron ine primary care perspective.

Methods: sources of l torature were scannla $=$ nd relevant material short-listed forfinten study from: (1) W/HO and (ind weisites; (2) PUBMED; and (3) papers inentioned in reforter e: of fu-text papers.

Resilt: 0, thiears of avian influenza in Asia and elsewhere indicate that the world (10) be moving towards a pandemic influenza outbreak. The WHO Global Influenza Preparedness Plan 2005 unifies the world with the vision of tackling the next pandemic influenza outbreak as a global effort that includes healthcare provider and patient alike.

Conclusions: We need to update ourselves and keep our staff and patients informed to make infection control measures part of our daily activities. In areas where there are contacts with animal reservoirs of influenza A, patients need to be reminded that they need to protect themselves from being infected.

(c) 2006 General Practice Airways Group. Published by Elsevier Ltd. All rights reserved.

\section{Contents}

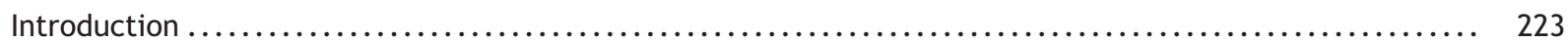

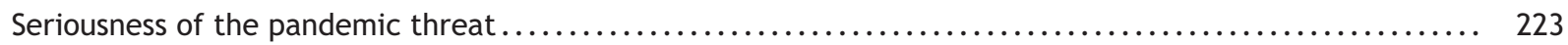

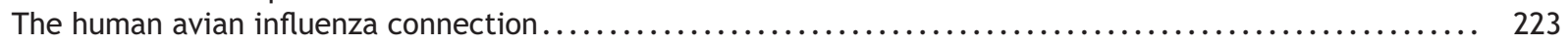

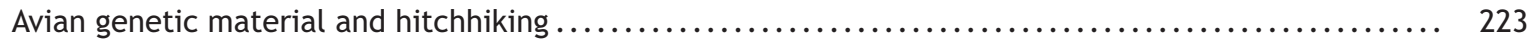

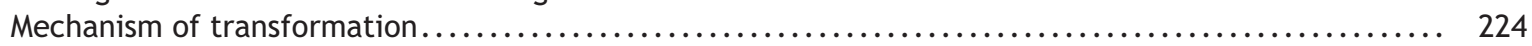

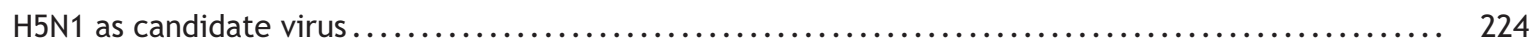

\footnotetext{
* Corresponding author. Tel.: +65 6516 4988; fax: +65 67791489 .

E-mail address: pakyean@starhub.net.sg (P.Y. Cheong).
} 


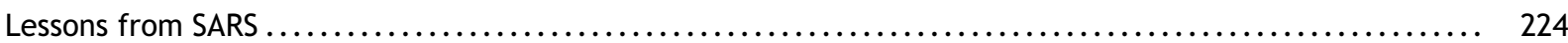

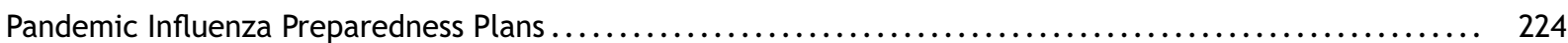

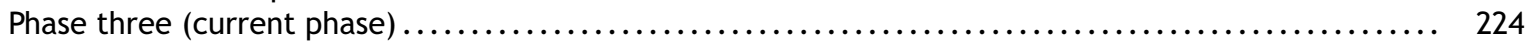

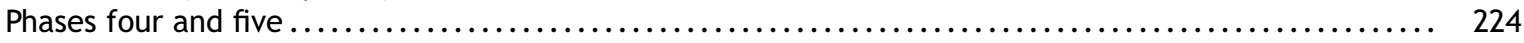

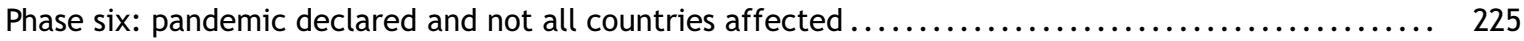

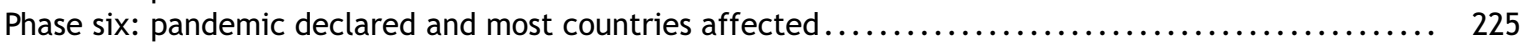

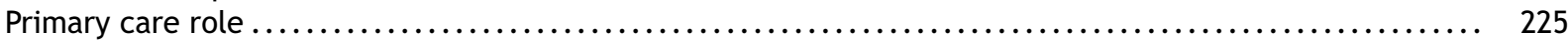

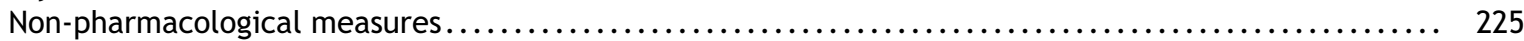

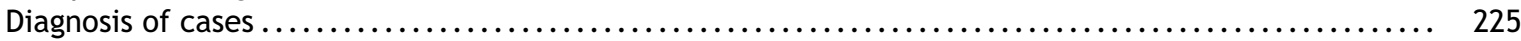

Steps to take if a novel influenza case is suspected during pandemic alert period $\ldots \ldots \ldots \ldots \ldots \ldots \ldots .225$

Novel virus suspected during pandemic period......................................... 226

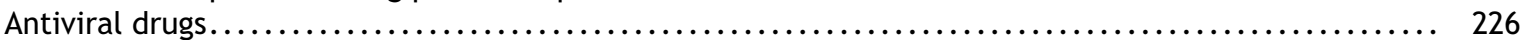

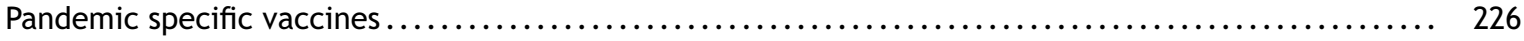

Delivery of effective health care ................................................... 226

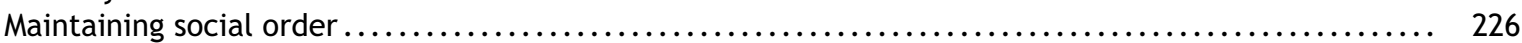

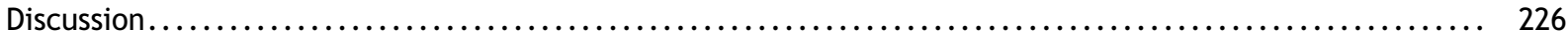

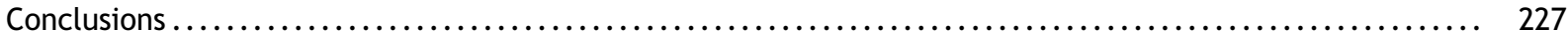

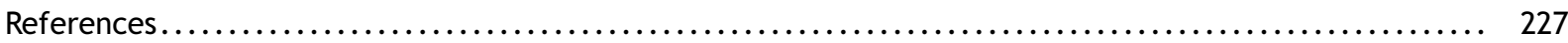

\section{Introduction}

There is a growing volume of medical literature related to the present pandemic influenza threat. The objective of this paper is to summarise this literature from the primary care perspective. Sources of literature were scanned and relevant material short-listed for further study from: (1) World Health Organisation (WHO) and Certer: for Disease Control and Preventi on (Lid) weusites; (2) PUBMED; and (3) C a pers mentioned in tine references of iull text papers. The infornation obtained was collated and crganized under the following headings:

- Seriousness of the pandemic influenza threat,

- The human avian influenza connection

- Lessons from Severe Acute Respiratory Syndrome (SARS)

- Pandemic preparedness and response plans

- Primary care role

\section{Seriousness of the pandemic threat}

WHO considers the current pandemic influenza risk to be serious [1]. Three pandemics occurred in the previous century: the "Spanish" flu in 1918 (with 40-50 million deaths worldwide); the "Asian" flu in 1957 (with 2 million deaths worldwide); and the "Hong Kong" flu in 1968 (with 1 million deaths worldwide) [2,3]. These had in common: high levels of illness in many countries; pressure on health services to cope with the illness generated by the pandemic; disruption to many aspects of daily life; and excess deaths $[3,4]$. It is now 38 years since the last pandemic. No one can be certain when the next pandemic will be due and how severe it will be [5].

\section{The human avianjinfgenta Connection Avial Senetic material and hitchhiking}

Ail inilinacerials from influenza pandemics of the previous century have avian genetic material present in them [6]. Most strains of influenza A virus are species specific, but some are able to jump species to infect humans. Given this "hitchhiking" propensity, the worldwide concern is that the human avian influenza outbreaks may be a step towards the next pandemic [9].

Since 1997, there has been an increasing number of outbreaks of highly pathogenic avian influenza (HPAl) among migratory waterfowl and also domestic poultry. There have also been human outbreaks of avian influenza [6-9]. The first H5N1 human avian influenza outbreak was in Hong Kong where 18 people were infected and of whom six subsequently died. The culling of 1.5 million chickens in just 3 days (29-31 December) was thought to have averted a potential pandemic [10].

The $\mathrm{H} 5 \mathrm{~N} 1$ virus continued to circulate amongst wild migratory birds. Since December 2003, it has caused die-backs of migratory birds and has killed millions of domestic fowl in Southeast Asia [11]. As of May 19 this year, 217 persons from Vietnam, Thailand, Cambodia, Indonesia, China, Turkey, Iraq, Azerbaijan, Egypt, and Djibouti have been infected. Of these, 123 have died, giving an average fatality rate of $57 \%$ [12]. 


\section{Mechanism of transformation}

Transformation from animal virus to a novel human virus in the last two pandemics is thought to be through the swapping of genetic material between two species-specific influenza viruses (called reassortment) in the same host (the "mixing vessel"), which could be human or pig [8-10]. The origin of the 1918 virus seems to be different. The novel virus was not the result of a re-assortment process. It appears to have been an avian-like influenza virus derived in toto from an unknown source $[13,14]$, as its eight genome segments are substantially different from contemporary avian influenza genes [4]. Avian viruses may not need to re-assort with a human virus first, nor do they require an intermediate mammalian host [15].

\section{$\mathrm{H} 5 \mathrm{~N} 1$ as candidate virus}

The H5N1 virus has the ability to infect human beings and the ability to cause severe disease. The third and remaining condition - not yet fulfilled - is the ability to transmit from human to human efficiently. Are we lucky so far or is the H5N1 virus not very capable of becoming a pandemic influenza virus? Only time will tell [7].

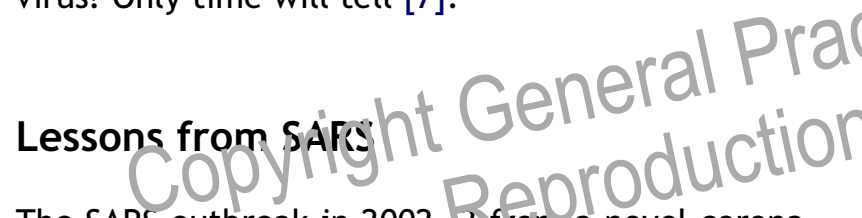

The SARS outbreak in 2002- 3 firm a novel corona virus resulted in 8098 cases and 774 deaths [11]. It taught us that:

- A highly pathogenic virus can catch healthcare providers off-guard and decimate their numbers if they are not protected by personal protective equipment [16].

- The SARS virus penetrated weak human defences because of atypical presentations, society's indecisions in responding to infection control, and laboratory security lapses.

- Collaboration amongst the world's scientists and healthcare workers was remarkable: the etiologic agent, a previously unrecognized coronavirus, was identified in March 2003 and sequenced within two weeks, and a vaccine candidate was developed by the following March [11].

- Rings of defence helped to control the spread of SARS into the community $[17,18]$.

The SARS virus declares its presence at the time when the patient is still not very infectious. In contrast, the influenza virus is infective one day before it declares its presence by inducing fever in the infected person [19]. Nevertheless, infection control measures are not totally in vain - at least they can prevent further spread.

The SARS outbreak and the present human avian influenza outbreaks, when compared with other epizoonotic infections that have disturbed mankind in recent years, have a message to tell: we need connected surveillance not only of human infections but also animal infections if we are to maintain control of our world [20]. In addition, primary care providers are in a good position to spread the message effectively to the patients they see that people in contact with animals need to make sure that they are aware of the importance of: avoidance of contact with animals; use of personal protective equipment when handling sick or dead animals; and hand washing.

\section{Pandemic Influenza Preparedness Plans}

WHO's 2005 edition of Gobal Influenza Preparedness Plan [21] redefined pandemic influenza in relation to the degree of risk (phase 1 to 610) Clnmal viruses transmittir. "totureans. The plan focuses on early efer: Guring a "pandemic alert" period (phases 3 to-5) when rapic, sP cordinated, global and national actions righ hevio contain or delay the spread of a $N \in W$ human influenza strain. Success will depend on surveillance in order to provide global early warning of human infections with new influenza subtypes.

\section{Phase three (current phase)}

The world is presently in WHO global pandemic phase 3. At this phase, WHO recommends vigilance for human cases in areas experiencing outbreaks in birds. Unaffected areas should undertake measures to prevent entry of the virus via poultry or wild birds, especially since this virus - H5N1 - once established in birds, has proved to be especially tenacious. For humans, no travel restrictions or screening measures at borders are recommended, as the risk that the virus will be carried by international travelers is considered negligible [22].

\section{Phases four and five}

Infection control measures aim to reduce transmission, and to prevent and delay further spread by rapid detection and isolation of persons infected with animal virus; tracing of close contacts 
during the patient's first two weeks of illness and voluntary quarantine of symptomatic patients for one week; use of antiviral drugs for treatment of cases and prophylaxis of others in the initially affected area; restriction on the movement of persons in and out of the initially affected area; and screening of travelers departing from areas where clusters of human cases are occurring [22].

\section{Phase six: pandemic declared and not all countries affected}

At the start of a pandemic, when not all countries or areas within a country are likely to have cases, WHO recommends that containment of infection be attempted by: use of personal protective equipment such as surgical masks or N95 respiratory masks; persons with fever and respiratory symptoms and their contacts be asked to undergo voluntary home confinement; deferment of non-essential domestic travel to affected parts of the country; and incoming travellers to be provided with health alert notices describing symptoms and where to report should these symptoms develop [22].

\section{Phase six: pandemic declared and most countries affected}

After a new pandel il Virus has spread iviclety, within countries and internatiomat(y), Whic may recommend that: isolation measures be stopped; health care workers and first responders to wear N95 respiratory masks and patients to wear surgical masks; should a large surge of cases occur, health care facilities should arrange beds to help to reduce transmission (for example, by keeping a distance between patient beds or placing adjacent beds face to foot); "social distancing" measures; the population to be reminded of the importance of frequent hand washing and the need for "respiratory hygiene"'; and mask wearing by the general population is not expected but permitted if people so wish [22].

\section{Primary care role}

The challenges facing primary care providers are many: early diagnosis of avian or pandemic influenza; surge of cases when the pandemic arrives; shortages of antivirals; shortages of personal protective equipment; maintenance of social order; and provision of continuation of care despite the surge of cases $[23,24]$.

\section{Non-pharmacological measures}

Non-pharmacological measures may be the only means of control that some countries have. These are useful from phase 3 to 6:

- Hand washing - washing hands frequently with soap and water reduces the spread of the virus from hands to the face, or to others.

- Respiratory hygiene - these constitute covering the mouth and nose when coughing, or sneezing with a tissue when possible, disposing of dirty tissue promptly by bag or bin, and washing the hands after handling the waste.

- Avoiding non-essential travel - non attendance at large gatherings such as concerts, theatres, cinemas, and sports arenas when one has an influenza-like illness.

- Avoidance of contact with birds of unknown infection status,

- Avoidance of eating of risky bird products, and

- Workplace infection control - voluntary isolation of workers exposed to fellow workers with fever and daily temperature monitoring.

\section{Diagnosis of cases}

In thase 3 acls, cases will be few so the case definition for a novel (i)fluenza infection requires both clinicitl dno epidiemiological criteria:

- Clinical criteria - fever, plus one or more of the following: sorethroat, cough and dyspnoea.

- Epidemiologic criteria - travel within the past 10 days to an HPAl outbreak area or human avian influenza outbreak area; and either direct contact with poultry (touching body, feces or contaminated surfaces, or eating uncooked poultry products) or close contact with a person with confirmed or suspected novel influenza. Occupational exposure through laboratory work with the novel influenza strain would also be considered an epidemiologic criterion, although this will be less commonly encountered.

In phase 6 when the infection has spread widely into the community, clinical criteria alone will suffice.

\section{Steps to take if a novel influenza case is suspected during pandemic alert period}

Once a patient is suspected of having a novel influenza strain during the pandemic alert period (phases 3-5), steps to be taken are [24]:

1. Control spread of infection. Check with the admitting hospital the arrangements for 
admission. Alternatively, take precautions to control infection through voluntary isolation at home.

2. Notify local or state public health departments. Report the suspicious case and ask for advice regarding the collection of laboratory specimens and treatment options.

3. Obtain clinical specimens requested by the public health department and arrange to have them transported to a designated public health laboratory.

4. Evaluate alternative diagnoses. A novel influenza infection can co-infect with a more common organism. Discontinue isolation and antiviral therapy prematurely only if an alternative diagnosis is confirmed with a highpredictive value test, the clinical course is explained by the alternative diagnosis, and the epidemiologic link to the novel influenza strain is not strong.

5. Start antiviral treatment as soon as possible. Work with the local health authority on this. The drug of choice presently is Tamiflu $75 \mathrm{mg}$ twice daily for five days in adults.

6. Assist the public health department in locating potentially exposed contacts and providing antiviral prophylaxis if recommended.

\section{Novel virus suspected durins, par arenuc} period

During the pandemic period (1, as 26), managing a patient with suspected novel influenza infection is different [24]:

1. Suspected cases need only meet the clinical criteria: fever with sore throat, cough, or dyspnoea. These criteria may be modified as the pandemic evolves.

2. Hospitalize only those patients with severe complications who cannot be cared for at home.

3. Submit clinical specimens to the designated laboratory only as requested by the public health department. Such monitoring will probably be needed only for a subset of patients to watch the epidemiology of the epidemic or to investigate unusual presentations or failures of preventive therapy.

4. Report atypical cases, prophylaxis failures, and other abnormal cases to the public health department.

\section{Antiviral drugs}

Antiviral drugs are likely to be the only major medical countermeasure available early in the pandemic. Where there is a shortage, the order of priority will be: (a) health workers because they will have a higher risk of exposure to the virus; (b) clinical risk groups - those in whom the pandemic virus will be more serious; and then (c) the general population, unless there are other reasons.

\section{Pandemic specific vaccines}

Once a pandemic virus is clearly identified, concerted international effort to develop an effective vaccine will commence. It will still take several months before vaccines specific to the novel virus become available.

\section{Delivery of effective health care}

Drugs and vaccines are important. Of equal importance is the appropriate arrangements for delivery of effective healthcare. Antiviral drugs need to be given within 48 hours of illness onset. A mass vaccination campaign will need to be delivered over a much shorter time than is the current practice. It will $\mathrm{fal}(\mathrm{b}=\mathrm{c} \mathrm{c} \mathrm{d}$. pimary care providers to delive?his.

\section{Maintaining soctelorder}

Th $=$ important actions to be taken in the pandemic period will be to minimize the social disruption and maintain social order. There will be a need to continue to provide routine care to patients despite the increase in demand for care from patients affected by the pandemic [23].

\section{Discussion}

The WHO and CDC websites are valuable information sources and we need to update ourselves and keep our staff and patients informed of the developments. Infection control measures need to become part of our behaviour. Patients need to be convinced that these are important daily activities. Where there is contact with animal reservoirs of influenza $A$, patients need to be reminded to protect themselves from being infected. The WHO Global Influenza Preparedness Plan 2005 unifies the world with the vision of tackling the next pandemic influenza outbreak as a global effort. Every primary care provider has a central role to play in emphasising patients' infection control efforts. 


\section{Conclusions}

The pandemic influenza threat is serious. Infection control measures remain important at the individual and community level. The spirit of voluntary isolation of symptomatic patients and contacts will reduce spread.

\section{References}

[1] WHO. How serious is the current pandemic risk? In: WHO. Avian influenza frequently asked questions, December 2005. URL: http://www.who.int/csr/disease/ avian_influenza/avian_faqs/en/index/html.

[2] Kilbourne ED. Influenza Pandemics of the 20th Century. Emerg Infect Dis 2006;12(1):9-14.

[3] WHO. Ten things you need to know about pandemic influenza, Oct 26, 2005. URL: http://www.who.int/csr/ disease/influenza/pandemic10things/en/print.html (accessed Jan 30 2006).

[4] Taubenberger JK, Morens DM. 1918 Influenza: the Mother of All Pandemics. Emerg Infect Dis 2006;2(1):15-22.

[5] Dowdie WR. Influenza Pandemic Periodicity, Virus Recycling, and the Art of Risk Assessment. Emerg Infect Dis 2006;12(1):34-9.

[6] Claas ECJ. Pandemic influenza is a zoonosis, as it requires introduction of avian-like gene segments in the human population. Vet Microbiology 2000;74:133-9.

[7] Webster RG, Peiris M, Chen H, Guan Y. H5N1 Outbreaks and Enzootic Influenza. Emerg Infect Dis 2006;12(1):3-8.

[8] Sampathkumar P. Avian H5N1 Influenza - Aite V.e Inching Closer to a Global Pardemic $N$ ivo C Cis Proc 2005;80:1552-6.

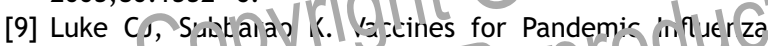
Emerg inf $f$ C $D$ is 2006;12(1):66-72

[10] Who. Avian influenza: assessing he pandemic threat, 29. Geneva: WHO/CDS; 2005. p. 8.

[11] Fauci AS. Pandemic Influenza Threat and Preparedness. Emerg Infect Dis 2006;12(1):73-7.
[12] WHO. Confirmed human cases of avian influenza (H5N1) May 2006 [cited 2006 May 19]. Available from http: / / www. who.int/csr/disease/avian_influenza/country/cases_table_ 2006_05_19/en/index.html (accessed Jan 30 2006).

[13] Taubenberger JK, Reid AH, Lourens RM, Wang R, Jin G, Fanning TG. Characteristics of the 1918 influenza virus polymerase genes. Nature 2005;437:889-93.

[14] Reid AH, Taubenberger JK, Fanning TG. Evidence of an absence: the genetic origins of the 1918 pandemic influenza virus. Nat Rev Microbiol 2004;2:909-14.

[15] Horimoto T, Kawaoka Y. Influenza: Lessons from past pandemics,warnings from current incidents. Nature 2005;3:591-600.

[16] Shaw K. The 2003 SARS outbreak and its impact on infection control practices. Public Health 2006;120(1):8-14.

[17] Cheong PY. SARS War - Defending the frontline. A Singapore Perspective. Prim Care Resp J 2004;13(2):106.

[18] James L, et al. Public health measures implemented during the SARS outbreak in Singapore 2003. Public Health 2006;120(1):20-6.

[19] WHO Writing Group. Non-pharmacological Interventions for Pandemic Influenza. International Measures. Emerg Infect Dis 2006;12(1):81-7.

[20] Gibbs EPJ. Emerging zoonotic epidemics in the interconnected global community. The Veterinary Record 2005;157:673-9.

[21] WHO. WHO Global influenza preparedness plan - The role of WHO and recommendations for national measures before and during pandemics. March, 2005. http://who. int/csr/resources/publications/intluen_a/ $N$ HO. CDS_CSR

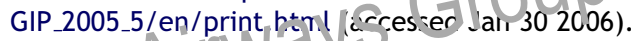

[22] WHO. Non-pha matos sical interventions: their role in relucing tiansmission and spread. November 2005. http://

Wno.int/csr/disea'se/a/licn_influenza/pharmaintervention

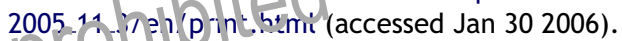

[Z.] H leniigo D. Influenza pandemics and avian flu. BMJ 2005;331:1066-9.

[24] Campos-Outcalt D. Pandemic influenza: how it would progress and what it would require of you. J Fam Pract 2005;54(12):1045-8.

Available online at www.sciencedirect.com ScienceDirect 